\title{
Morphological and Morphometrical Characteristics of Particulate Solids To Recycle Resulting from Electric Cables Crio-comminution.
}
Alessandra Gaeta, Silvia Serranti, Paolo Massacci, Giuseppe Bonifazi.
Dipartimento di Ingegneria Chimica, dei Materiali, delle Materie Prime e Metallurgia, Università degli Studi di Roma "La Sapienza", Via Eudossiana, 18, 00184 Rome, Italy, Telephone: +39.06.44585.925 Fax:+39.06.44585.618 e-mail: giuseppe.bonifazi@uniroma1.it
Waste disposal is nowadays a well-known critical problem for environmental protection. For this reason, in the last years, the research in the field of waste recycling increased more and more with the specific target to find solutions oriented to reduce the environmental impact of waste and to recover precious metals and other useful materials. In this perspective it assumes great importance the possibility to recover waste products resulting from material goods dismantling, or from products at the end of their "life cycle", or simply from "common" household or industrial waste [1]. Electric cables represent a great family belonging to such a class of products.

The possibility to recover metals from electric cables has been investigated in this work. Electric cables are usually constituted by various components, different for chemical-physical attributes, that is: i) conductors (i.e. copper or aluminum), ii) shield materials, usually metallic, iii) insulating materials (i.e. PVC, PE, rubber) and iv) coating materials (i.e plastic or metals). The study was particularly addressed to verify the effect of the comminution of such products when performed at different temperatures, ranging from room up to criogenic conditions, utilizing different cooling media as $\mathrm{CO}_{2}\left(-20^{\circ} \mathrm{C}\right)$ and nitrogen $\left(-100^{\circ} \mathrm{C}\right)$. More specifically the parameters investigated have been particles morphological and morphometrical attributes and their degree of liberation, being these parameters of primarily importance in respect of the further electrostatic separation processes (particle surface charge and flow modalities) and final reuse (mixture properties).

A systematic imaging based procedure [2] was applied on the particle products [3] resulting from the different criogenic comminution tests. Results envisaged as particles present a different shape (Figure 1) according to the different comminution temperature applied (Figure 2). Particle profile roughness seems to be particularly influenced by temperature (Figure 3). More specifically the results obtained through criogenic comminution show, in average, a lower size class distribution for the products in comparison with those obtainable at room temperature. Moving from room temperature to $\mathrm{CO}_{2}$ and nitrogen environmetal controlled comminution, particles show a decreasing value of fractal dimension [4], of Feret diameter and of the area/perimeter ratio. Such results have to be economically analyzed and compared in respect of the different level of energy required for the two approaches.

[1] W.L. Dalmijn, J.A. van Houwelingen, Metal Recovery From Car Scrap and Other Sources, Advances in Recovery and Recycling: REC'95. Geneve, Switzerland 1 (1993) 19-22.

[2] W.K. Pratt, Digital Image Processing, $2^{\text {nd }}$ edition, John Wiley \& Sons Inc., New York, 1991.

[3] G. Bonifazi, P. Massacci, Particle Identification by Image Processing. KONA No. 14, Powder and Particle. Osaka, Japan (1996) 109-129.

[4] B.H. Kaye, A Random Walk Through Fractal Dimensions, VCH Publishers, Weinhein, 1989. 


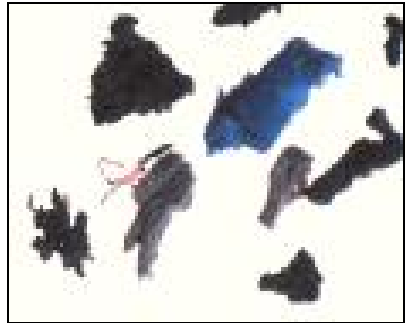

1a

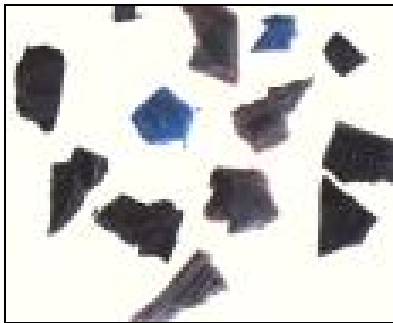

$1 \mathrm{~b}$

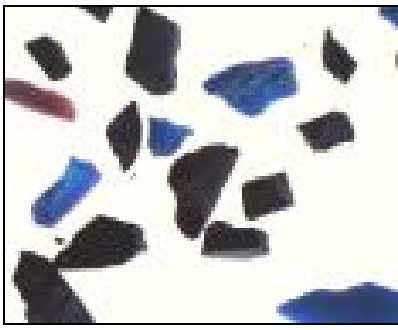

$1 \mathrm{c}$

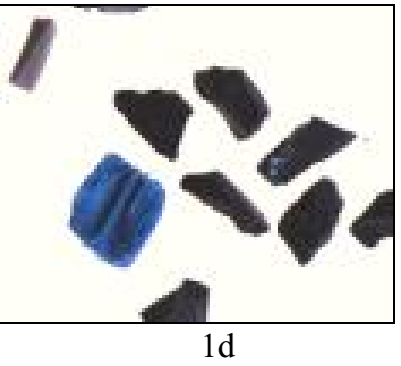

$1 \mathrm{~d}$

Figure 1 - Image sequence showing the different morphological attributes of the different particles, of electric cables to recycle, resulting from comminution, performed at different temperatures. 1a: room temperature; $1 \mathrm{~b}$ : using as cooling media $\mathrm{CO}_{2} ;\left(-20^{\circ} \mathrm{C}\right) ; 1 \mathrm{c}$ : using as cooling media nitrogen $\left(-100^{\circ} \mathrm{C}\right)$ and $1 \mathrm{~d}$ : pre-cooled with nitrogen and milled using $\mathrm{CO}_{2}$.

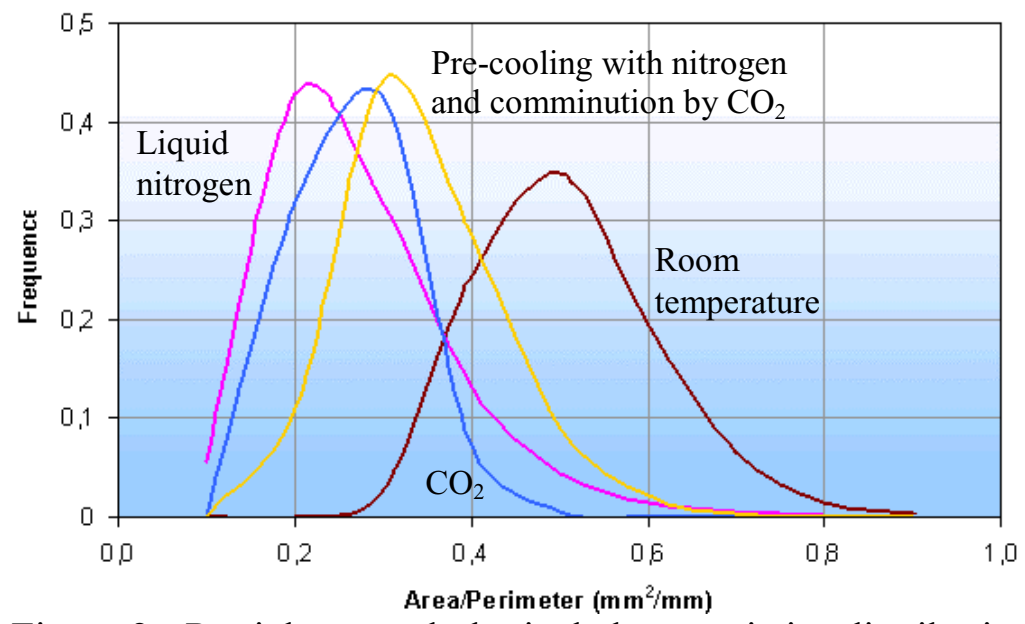

Figure 2 - Particles morphological characteristics distribution according to the comminution actions performed at different temperature. Particles resulting from "nitrogen" comminution show lower area/perimeter ration, indicating a more non homogeneous particle shape. Particles resulting from room temperature comminution present an opposite behaviour.

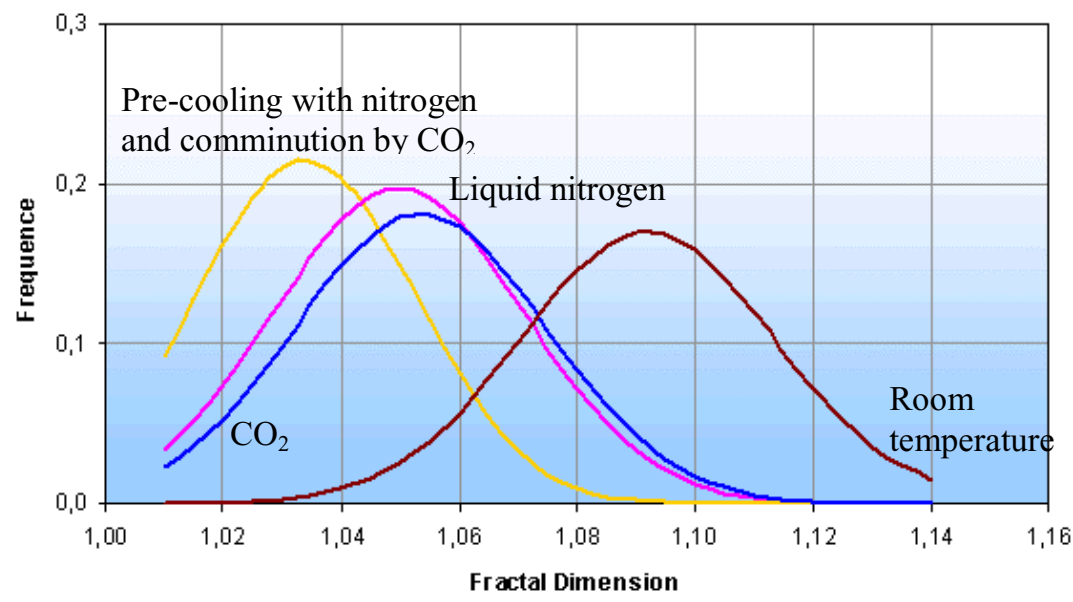

Figure 3 - Fractal dimension distribution of the particulate products resulting from different comminution actions (different temperature). Increasing the cooling particles present a more regular shape, such an aspect strongly influences the further separation performed by electrostatic separators. 